\title{
Smart Bio-palladium nano materials synthesis by green method
}

\begin{abstract}
Smart palladium nanoparticles (PdNPs) are of special interest due to their distinctive characteristics and a large unfold of applications. PdNPs are synthesized by the conventional physical and chemical methods. These methods have several drawbacks and thus, biological methods are found to be substitute to the conventional methods. Biological method may be an easy, reliable, non-toxic and eco-friendly for synthesis of smart nanomaterials. Bacterial cells and plant materials are widely used as potential reducing agents for PdNPs synthesis. However, molecular mechanisms concerned in PdNPs synthesis don't seem to be well understood and special efforts are needed more.
\end{abstract}

Keywords: Palladium nanoparticles, Eco-friendly, Plant, Microorganisms, Nanomaterials
Volume 3 Issue 3 - 2016

\author{
Bankar AshokV \\ Department of Microbiology, Savitribai Phule Pune University, \\ India \\ Correspondence: Bankar Ashok V, Department of \\ Microbiology,WCS, Savitribai Phule Pune University, Pune, \\ Maharashtra, India Email ashok@unipune.ac.in
}

Received: February 05, 2016 | Published: April 04, 2016

\section{Editorial}

Nobel metallic nanomaterials like palladium nanoparticles (PdNPs) are gaining a special attention from scientific community owing to their distinctive physical, chemical and optical properties. ${ }^{1}$ Such smart Pd nanomaterials are use in surface-enhanced Raman scattering, catalysis, fuel cells, hydrogen storage, chemical/biological sensing, plasmonic wave guiding, drug delivery, magnetic recordings, chemo-optical transducers, environmental protection and cancer therapy. ${ }^{2,3}$ The conventional physical and chemical methods like sol-gel synthesis, aerosol technology, lithography, laser ablation, chemical reduction, electrochemical and polyol etc. are employed for nanomaterials synthesis. These methods require expensive chemicals and high consumption of energy underneath extreme conditions. The hazardous chemicals like organic solvents, reducing agents and stabilizers are getting used for nanoparticles synthesis and to forestall agglomeration of colloids. The formation of smart nanomaterials along with deadly chemicals is preventing their clinical and biomedical applications ${ }^{4,5}$ A continual effort is needed for developing easy, clean, reliable, biological compatible and eco-friendly methodology for smart nanomaterials synthesis. ${ }^{6}$

Biological approach could be an inexperienced, eco-friendly, non-toxic and efficient and a suitable substitute to the conventional methods for nanomaterials synthesis. Biological systems like bacteria, fungi, algae and plant materials. ${ }^{7-9}$ are being used for nanomaterials synthesis. The knowledge base approach between microbiology and material science offers a breathtaking prospect for several researchers to urge engaging nanomaterials. Interestingly, a bacterial system is one in every of the reducing agents for inorganic nanoparticles synthesis. A bacterial system may be a promising "micro-factory" to allow high yields of smart nanomaterials. Bacterial cells have some helpful options as follows:

\section{They're long within the atmosphere}
a. Adapt simply to extreme conditions
b. Quick-growing
c. Cheap to cultivate and
d. Easy to manipulate.

The metal-reducing bacteria became a special attraction in recent years because of their ability for electricity generation and wastes removal. Bacterial system intercede nanoparticles are rapidly developing research area in a green nanotechnology. ${ }^{10,11}$ Bacterial cells like Pseudomonas, Escherichia coli, Desulfovibrio desulfuricans, Shewanella oneidensis, Clostridium butyricum, Citrobacter braakii, Enterococcus faecium, Bacteroides vulgates, Bacillus sphaericus and Geobacter sulfurreducens. ${ }^{12-16}$ are well studied 'green materials' for PdNPs synthesis. The formation of PdNPs by $D$. desulfuricans was probably due to the enzyme hydrogenlyase. ${ }^{14} S$. oneidensis cells are used for bio-PdNPs and bio$\mathrm{Pd} / \mathrm{Au}$ NPs synthesis and employed in dechlorination of pollutants. ${ }^{15,17}$ $\mathrm{Cr}$ (VI) is one of the toxic metals widely used in leather industries and incessantly discharges into wastewater. ${ }^{18} \mathrm{Cr}$ (VI) metal ions are reduced by PdNPs prepared from plant G. sulfurreducens. ${ }^{19}$ Metallic $\mathrm{Pd}$ and Pd-AuNPs were synthesized under ambient conditions with $S$. oneidensis. These nanocomposites have demonstrated excellent catalytic activities for reduction of various nitroarenes..$^{20} \mathrm{Au}$-rich core and Pd-rich shell type nanomaterials formed by E. Coli cells are used as catalysts for the oxidation of benzyl alcohol. ${ }^{21}$ PdNPs formed by bacteria like G. sulfurreducens and E. Coli are employed in a variety of chemical reactions including Heck couplings .22,23

Plant material is another excellent 'green source' for PdNPs synthesis in green nanotechnology. Therefore, the biological approach for nanomaterials synthesis by using plant materials is a good substitute to the conventional chemical methods. Plants mediate nanoparticles synthesis technique is quicker, more economical, efficient and simple to rescale in massive quantities. ${ }^{24}$ Plant extracts are useful 'green material' as result of they contain each reducing and stabilising agents for nanoparticles formation. ${ }^{25}$ Therefore, a range of plant extracts of Cinnamon zeylanicum bark, Annona squamosa peel, Coffea arabica, Camellia sinensis, Gardenia jasminoides, Curcuma longa tuber, Gardenia jasminoides leaf, Glycine max leaf, Cinnamomum Camphora leaf, Asparagus racemosus root and banana peel are used for PdNPs synthesis of different size and shape. ${ }^{7,25-30}$ Bio-PdNPs formed by living plants, Colocasia esculentaleafand Euphorbia granulateextract are employed in a variety of Suzuki-Miyaura coupling reactions.$^{31-33}$ Similarly, PdNPs synthesised by an aqueous solution of Pulicaria glutinosa and watermelon rind have incontestible a wonderful catalysts for the Suzuki coupling reaction. ${ }^{34,35}$ Bio-PdNPs synthesized by Delonix regia leaf extract have also demonstrated a catalytic activity for nitroaromatic hydrogenation. ${ }^{36}$ Green synthesis of PdNPs by employing a gum ghatti (Anogeissus latifolia) showed a superior antioxidant 
property even at lower concentration. They even have demonstrated a catalytic activity for reduction of dyes like methyl orange, methylene blue, coomassie brilliant blue G-250 and 4-nitrophenol with sodium borohydride.$^{37} \mathrm{PdNPs}$ produced by Xanthan gum showed a catalytic activity towards the reduction of 4-nitrophenol to 4-aminophenol. ${ }^{38}$ The biogenic PdNPs formed by using leaf aqueous extract of Eclipta prostrate have demonstrated the antiplasmodial activity against Plasmodium berghei in Swiss albino mice. ${ }^{39}$ PdNPs synthesized by Azadirachta indica extract used as catalysts within the formation of imine derivatives without any surface change. ${ }^{40}$ Thus, bio-Pd nanoparticles are synthesized by green materials having a variety of applications. Bacterial cells and plant materials are widely studied 'green sources' for PdNPs synthesis. Other green sources like yeasts, fungi, algae and viruses are needed to be explored for PdNPs synthesis in future. The main points of molecular mechanisms concerned in metal nanoparticles synthesis aren't nonetheless alright and more research work needed further. ${ }^{41}$

\section{Acknowledgments}

Author would like to acknowledge BCUD, Savitribai Phule Pune University for funding support to Dr Ashok Bankar in form of BCUD Project for Teachers.

\section{Conflicts of interest}

None.

\section{References}

1. Cheong S, Watt JD, Tilley RD Shape control of platinum and palladium nanoparticles for catalysis. Nanoscale. 2010;2:2045-2053.

2. AlbiterMA,ZaeraFAdsorption properties of supported platinum catalysts prepared using dendrimers. Langmuir. 2010;26(21):16206-16210.

3. West PR, Ishii $S, N$ aik $G V$ et al. Searching for better plasmonic materials. Laser Photonics Rev. 2010;4(6):795-808.

4. Nguyen VL, Nguyen DC, Hirata $\mathrm{H}$ et al. Chemical synthesis and characterization of palladium nanoparticles. Adv Nat Sci Nanosci Nanotechnol. 2010;1(3):1-5.

5. Cha JH, Kim KS, Choi S et al. Size-controlled electrochemical synthesis of palladium nanoparticles using morpholinium ionic liquid. Korean $J$ Chem Eng. 2007;24(6):1089-1094.

6. Kulkarni N, Muddapur U Biosynthesis of metal nanoparticles: A review. J Nanotechnol. 2014;1-8.

7. Bankar A, Joshi B, Kumar AR et al. Banana peel extract mediated novel route for the synthesis of palladium nanoparticles. Mater Lett. 2010;64(18):1951-1953.

8. Momeni S, Nabipour I A simple green synthesis of palladium nanoparticles with Sargassum alga and their electrocatalytic activities towards hydrogen peroxide. Appl Biochem Biotechnol. 2015;176(7):1937-1949.

9. Pantidos N, Horsfall LE Biological synthesis of metallic nanoparticles by bacteria, fungi and plants. J Nanomed Nanotechnol 5(233). 2014

10. He S, Guo Z, Zhang Y et al. Biosynthesis of gold nanoparticles using the bacteria Rhodopseudomonas capsulata. Mater Lett. 2007;61(18):3984-3987.

11. Iravani S Bacteria in nanoparticle synthesis: current status and future prospects. Int Schol Res Not. 2014;1-18

12. Schlüter M, Hentzel T, Suarez C et al. Synthesis of novel palladium(0) nanocatalysts by microorganisms from heavy-metal influenced highalpine sites for dehalogenation of polychlorinated dioxins. Chemosphere. 2014;117:462-470.
13. Lloyd JR, Yong P, Macaskie LE Enzymatic recovery of elemental palladium by using sulfate-reducing bacteria. Appl Environ Microbiol. 1998;64(11):4607-4609

14. Yong P, Rowson NA, Farr JPG et al. Bioaccumulation of palladium by Desulfovibrio desulfuricans. $J$ Chem Technol Biotechnol. 2002;77(5):593-601.

15. De Windt W, Aelterman P, Verstraete W Bioreductive deposition of palladium (0) nanoparticles on Shewanella oneidensis with catalytic activity towards reductive dechlorination of polychlorinated biphenyls. Environ Microbiol. 2005;7(3):314-325.

16. Hennebel T, Nevel SV, Verschuere S et al. Palladium nanoparticles produced by fermentatively cultivated bacteria as catalyst for diatrizoate removal with biogenic hydrogen. Appl Microbiol Biotechnol. 2011;91(5):1435-1445.

17. De Corte S, Hennebel T, Fitts JP et al. Biosupported bimetallic Pd$\mathrm{Au}$ nanocatalysts for dechlorination of environmental contaminants. Environ Sci Technol. 2011;45(19):8506-8513.

18. Bankar AV, Kumar AR, Zinjarde SS Removal of chromium (VI) ions from aqueous solution by adsorption onto two marine isolates of Yarrowia lipolytica. J Haz Mater. 2009;170(1):487-494.

19. Tuo Y, Liu GF, Zhou JT et al. Microbial formation of palladium nanoparticles by Geobacter Sulfurreducens for chromate reduction. Biores Technol. 2013;133:606-611.

20. Tuo Y, Liu G, Dong B et al. Microbial synthesis of $\mathrm{Pd} / \mathrm{Fe} 3 \mathrm{O} 4, \mathrm{Au} /$ $\mathrm{Fe} 3 \mathrm{O} 4$ and $\mathrm{PdAu} / \mathrm{Fe} 3 \mathrm{O} 4$ nanocomposites for catalytic reduction of nitroaromatic compounds. Sci Rep. 2015;5:13515.

21. Deplanche K, Merroun ML, Casadesus M et al. Microbial synthesis of core/shell gold/palladium nanoparticles for applications in green chemistry. J R Soc Interface. 2012;9(72):1705-1712.

22. Coker VS, Bennett JA, Telling ND et al. Microbial engineering of nanoheterostructures: Biological synthesis of a magnetically recoverable palladium nanocatalyst. ACS Nano. 2010;4(5):2577-2584.

23. Foulkes JM, Malone KJ, Coker VS et al. Engineering a biometallic whole cell catalyst for enantio selective deracemization reactions. ACS Catalysis. 2011;1:1589-1594.

24. Jha AK, Prasad K, Kulkarni AR Plant system: Nature's nanofactory. Colloids Surf Biointerfaces. 2009;73(2): 219-223.

25. Sathishkumar M, Sneha K, Yun YS Palladium nanocrystals synthesisusing Curcuma longa tuber extract. Int $J$ Mater Sci. 2009;4:11-17.

26. Roopan SM, Bharathi A, Kumar R et al. Acaricidal, insecticidal, and larvicidal efficacy of aqueous extract of Annona squamosa $\mathrm{L}$ peel as biomaterial for the reduction of palladium salts into nanoparticles. Colloids Surf B Biointerfaces. 2011;92:209-212.

27. Nadagouda MN, Varma RS Green synthesis of silver and palladium nanoparticles at room temperature using coffee and tea extract. Green Chem. 2008;10:859-862.

28. Jia L, Zhang Q, Li Q, Song $\mathrm{H}$ The biosynthesis of palladium nanoparticles by antioxidants in Gardenia jasminoides Ellis: Long life time nanocatalysts for p-nitrotoluene hydrogenation. Nanotechnology. 2009;20(38):385601.

29. Petla RK, Vivekanandhan S, Misra M et al. Soybean (Glycine max) leaf extract based green synthesis of palladium nanoparticles. $J$ Biomater Nanobiotechnol. 2012;3(1):14-19.

30. Raut RW, Ansari SM, Haroon SA, et al. Rapid biosynthesis of platinum and palladium metal nanoparticles using root extract of Asparagus racemosus Linn. Adv Mat Lett. 2013;4(8):650-654.

31. Parker HL, Rylott EL, Hunt AJ et al. Supported palladium nanoparticles synthesized by living plants as a catalyst for Suzuki-Miyaura reactions. PLoS One. 2014;9(1):e87192. 
32. Nasrollahzadeh M, Sajadi S Pd nanoparticles synthesized in situ with the use of Euphorbia granulate leaf extract: Catalytic properties of the resulting particles. J Colloid Interface Sci. 2016;462:243-251.

33. Borah RK, Saikia HJ, Mahanta A et al. Biosynthesis of poly(ethylene glycol)-supported palladium nanoparticles using Colocasia esculenta leaf extract and their catalytic activity for Suzuki-Miyaura cross-coupling reactions. $R S C A d v$. 2015;5:72453-72457.

34. Khan M, Kuniyil M, Adil SF et al. Biogenic synthesis of palladium nanoparticles using Pulicaria glutinosa extract and their catalytic activity towards the Suzuki coupling reaction. Dalton Trans. 2014;43(24):9026-9031.

35. Lakshmipathy R, Reddy BP, Sarada NC et al. Watermelon rind-mediated green synthesis of noble palladium nanoparticles: catalytic application. Appl Nanosci. 2015;5(2):223-228.

36. Dauthal P, Mukhopadhyay M Biosynthesis of palladium nanoparticles using Delonix regia leaf extract and its catalytic activity for nitroaromatics hydrogenation. Ind Eng Chem Res. 2013;52(51):18131-18139.
37. Kora AJ, Rastogi L Green synthesis of palladium nanoparticles using gum ghatti (Anogeissus latifolia) and its application as an antioxidant and catalyst. Arabian J Chem. 2015

38. Santoshikumari A, Venkatesham M, Ayodhya D et al. Green synthesis, characterization and catalytic activity of palladium nanoparticles by xanthan gum. Appl Nanosci. 2015;5(3):315-320.

39. Rajakumar G, Rahuman AA, Chung M et al. Antiplasmodial activity of eco-friendly synthesized palladium nanoparticles using Eclipta prostrata extract against Plasmodium berghei in Swiss albino mice. Parasitol Res. 2015;114(4):1397-1406.

40. Joseph KC, Edayadulla N, Kumar G et al. The catalytic activity of biomediated palladium nanoparticles on imine formation reactions. Sci Adv Meter. 2014;6(3):483-491.

41. Kirsner RS, Orsted H, Wright JB Matrix metalloproteinases in normal and impaired wound healing: A potential role of nanocrystalline silver. Wounds. 2001;13(Suppl C): 4-14. 